\title{
Closing the Gap between 'Expert' and 'Lay' Knowledge in the Governance of Wastewater: Lessons and Reflections from New Delhi
}

\author{
Tim Karpouzoglou and Anna Zimmer
}

\begin{abstract}
The wastewater crisis in megacities of the Global South is increasingly recognised. However, sector-driven approaches (of river pollution, sewerage, or city-wide drainage) have had limited success in tackling this multifaceted problem. This article seeks to dynamise debates by positioning the current crisis in relation to contests of knowledge. Focusing on wastewater governance in Delhi, the article explores the question which different knowledges about wastewater exist in scientific communities, governments, and amongst citizens. What is frequently understood as 'expert' knowledge of the Central Pollution Control Board, is juxtaposed with the 'lay' experiences of citizens residing in one unauthorised colony in East Delhi. Exploring both, the article provides insights on the mechanisms through which community experiences are excluded from policy deliberations, leading to major wastewater-related problems being overlooked. The article then calls for enhanced attention to knowledge integration, thus strengthening the participation of citizens in formulation and implementation of wastewater programmes.
\end{abstract}

In recent years there has been an increasing recognition of a contemporary crisis in managing untreated wastewater in megacities of the Global South through various policy channels. However, sector-driven approaches (such as in the area of river pollution, sewerage, and city-wide drainage) have had limited success in tackling the multifaceted problems posed by untreated wastewater effectively. Against this background, this article seeks to dynamise ongoing debates by positioning the current crisis in relation to particular contests of knowledge. Focusing on wastewater governance in Delhi, it explores the following question: What are the different knowledges about wastewater that exist in scientific communities, governments, and amongst citizens? What is frequently understood as 'expert' knowledge of the scientists working for the national environmental regulatory authority, the Central Pollution Control Board, is juxtaposed with the 'lay' experiences of poorer citizens residing in one of the poorer colonies in East Delhi. Exploring the divide between both, the article provides valuable insights on the mechanisms through which community experiences tend to be excluded from policy deliberations, leading to major local wastewaterrelated problems being overlooked. By exploring the knowledge creation that takes place nationally, at the city and in the poorer colonies, the purpose is to provide a more detailed account of the contradictions which arise between the different 'truths', 'realities' and 'imaginaries' on wastewater. The article calls then for enhanced attention to knowledge integration in policy and formal decision-making processes, and resonates strongly with the New Delhi Statement call for strengthening the participation of citizens in the implementation of water and sanitation programmes.

\section{Introduction}

More than 20 years have now elapsed since the New Delhi Statement endorsed, as one of its guiding principles, 'the protection of the environment and safeguarding of health through the integrated management of water resources, liquid and solid wastes' (United Nations 1990). 
Taking a closer look at the wastewater scenario in New Delhi today, this article suggests that achieving this principle is still just as relevant. Against this background, we argue that a deeper reflection of the role of knowledge in policymaking is needed to better address the complex challenges posed by untreated wastewater.

At present, untreated wastewater in the Indian capital contributes to urban environmental degradation and is linked to the transformation of river bodies into 'drains', receiving the bulk of domestic and industrial liquid waste. As a result, and despite the city of New Delhi alone having 40 per cent of the total sewerage treatment infrastructure in the country, only 45 per cent of the sewerage generated is treated, while the rest is discharged directly into the Yamuna river (CPCB 2004). The Delhi segment of the Yamuna river is declared 'biologically' a dead river, with levels of dissolved oxygen (essential for the preservation of aquatic life and river ecology) reaching zero once the river passes through the city (CSE 2007: 89). Perhaps less recognised than the ecological implications of untreated wastewater, are the impacts upon Delhi's poorer citizens. A large section of Delhi's middle class lives in the formally planned colonies and residential suburbs and has successfully claimed its own access to wastewater treatment infrastructures that the municipal corporations are legally obliged to provide (Chaplin 2011). In the slums, in contrast, sanitation coverage drops drastically. For example, the National Sample Survey Organisation (NSSO 2003: 29) estimates that none of the notified (i.e. controlled development areas), and only 3 per cent of nonnotified slums in Delhi are connected to underground sewerage lines, indicating that the poor are much more exposed to untreated wastewater, often contributing to higher morbidity of residents in slums (Singh 2009: 207, 212). In line with this finding, Sakdapolrak (2010: 317) shows how slum residents in Chennai bear catastrophic economic costs of the disease burden, with up to 22 per cent of monthly incomes lost due to direct or indirect costs of ill-health.

Explanations of the wastewater crisis emanating from the New Delhi planning and engineering community continue to place a strong emphasis on the need to overcome current 'failures' in implementation. One narrative in support of the implementation failure argument is the lack of political will' (McGranahan et al. 2001) among city authorities and the lower strata of the bureaucracy, to implement nationally led programmes (e.g. river cleaning programmes), a procedural difficulty partly explained by the fact that 'faeces' are still largely a taboo subject (Black and Fawcett 2008). Another narrative that has gained particular prominence is the need to augment wastewater infrastructures in order to meet new demands for wastewater treatment posed by the growth of Delhi's population (Chandra and Aneja 2004: 2; Singh 2009: 5). Solutions to the escalating problem of untreated wastewater are thus perceived to flow almost entirely from higher financial investments in wastewater treatment (Banerjee 2001: 98; McGranahan et al. 2001: 5; Prasad 2002; Deb 2004; Mavalankar and Shankar 2004: 318). The recent 'interceptor sewer project' is a product of this policy mindset, which at an estimated cost exceeding US $\$ 1$ billion, aspires to augment Delhi's wastewater treatment capacity through heavy emphasis on building large-scale infrastructures such as sewage treatment plants (STPs) and drains to divert wastewater from entering the Yamuna river (Engineers India Ltd. and CH2M Hill (India) Pvt Ltd. 2008; CSE 2009). It is reasonable, however, to question whether an exclusive emphasis on hard engineering solutions is likely to resolve Delhi's wastewater crisis, given that a large section of Delhi's poorer citizens still remains unconnected to the city sewerage network (Zimmer forthcoming).

As a consequence of the aforementioned discourse, the policy approaches are rarely problematised. Given the authors' more sceptical outlook towards the way the wastewater crisis is presently framed within Delhi's policy circles, our interest is therefore to broaden the debate. The New Delhi Statement already acknowledged that to address the basic human need for sanitation, the way forward was to build on 'indigenous knowledge' (Principle 1, United Nations 1990: 4). In Principle 3, it put further emphasis on the fact that 'communities should have prominent roles in planning' in order to achieve sustainable solutions (United Nations 1990: 5). Recent debates on urban governance have given further weight to the role of knowledge, stating that inclusive governance cannot take place if different kinds of knowledge are not integrated (Baud 2011). 
However, this integration faces difficulties, as different knowledges around wastewater are often attached to different claims to power, authority and legitimacy (Keeley and Scoones 1999; Baud 2011). Research conducted in Delhi is used to demonstrate that 'expert' knowledge (linked primarily to the planning and engineering disciplines) has been much more dominant in policy deliberations related to wastewater management, despite the inherent uncertainties and limitations of relying solely on the knowledge of expert practitioners (Prakash 1999; Movik and Mehta 2009). In contrast, the knowledge of marginalised groups routinely exposed to wastewater, or otherwise defined in this article as 'lay' knowledge, has very limited success in being recognised by state representatives. This article later argues that there is significant value in this knowledge, as it demonstrates the complex relationships and interactions of poorer citizens with the state as they struggle to resolve difficulties presented by wastewater overflow and stagnation. It further illustrates the inherent limitations of expert-led policy responses to adequately capture the practical, social and health dimensions of living with waste(water) in the poorer unauthorised colonies of Delhi.

The article examines this 'expert' vs 'lay' dichotomy ${ }^{1}$ and how it relates to the governance of wastewater in a number of ways. We do this in section 2 by describing the nature of debates on managing wastewater that have taken place in Delhi and which are ongoing. In section 3, we describe the type of narratives and problematising of wastewater that are representative of the 'expert' knowledge of scientists, drawing insights from scientists working for India's national environmental regulatory body, the Central Pollution Control Board. Section 4 brings to the foreground local perspectives that suggest a very different way of problematising wastewater. Juxtaposing the 'expert' knowledge of scientists with the 'lay' knowledge of poorer citizens is useful for illustrating the type of mismatches and contradictions in the way different actor groups presently perceive problems related to wastewater, as well as the mechanisms through which exclusion of certain types of knowledge take place. In our view, a better appreciation of these contradictions is central for democratising decision-making processes and thus granting policy formulation greater legitimacy.

\section{Conflicting views on wastewater: The debates at the city-level}

Mapping the policies and interventions around wastewater in Delhi today, we witness that government agencies' rather fragmented way of dealing with wastewater problems is often in strong opposition to the views of environmental non-governmental organisations (NGOs) and civil society representatives. Debates at city-level are thus rather politicised, especially with regard to Delhi's main river, the Yamuna.

Endless numbers of court cases have been filed against the government by activists such as M.C. Mehta and the NGO Paani Morcha, to push for the effective protection and restoration of the Yamuna (Dutta and Peace Institute Charitable Trust 2009). Addressing these concerns, however, the Delhi Jal Board (DJB, the city water authority) understands the problem of wastewater and the pollution it causes in Delhi's main water bodies purely as an infrastructural concern to be dealt with through extension of the sewerage network and more efficient management of existing drainage. The installation of three major interceptor sewers along the main drains to capture the wastewater from the 'unsewered' areas retains a similar mission (Engineers India Ltd and CH2M Hill (India) Pvt Ltd 2008). These are meant to solve the river pollution issue, but in the process give up on the aim of sewering the whole city - a very stark showpiece of neglecting the social dimension of the wastewater crisis while retaining an exclusive focus on the 'biophysical' dimensions.

Yet, even those are not dealt with effectively, as demonstrated by the fact that the Yamuna river continues to remain heavily polluted, despite past attempts at river 'clean-ups'. Criticism of DJB's practices therefore mostly comes from environmental NGOs such as the prominent Centre for Science and Environment (CSE). Their belief in DJB's capacity to tackle the pollution of the Yamuna is almost nil: 'As tales of the Yamuna show there is never enough money to intercept, convey, collect and treat all the sewage we generate' (CSE 2007: 1). Instead of focusing on more investments for further sewer lines and sewage treatment plants, a profound paradigm shift is advocated to reach a solution that starts tackling the problem at its source - in or near the households that produce wastewater. 
The strong focus on infrastructure is also visible in the Irrigation and Flood Control Department at State level or the Engineering Wing of the Municipal Corporation of Delhi (MCD), responsible for open or covered rainwater drains, which, in the absence of sewer lines, in fact also discharge municipal wastewaters. At stake here is not the pollution of the river Yamuna, but rather, the wastewater situation in residential areas. In the perspective of these actors, infrastructure assets take a value of their own, as shown in this statement by an engineer with reference to a blocked drain in a slum area: 'If the people can be disconnected then most problems will be resolved'. ${ }^{2}$ Health concerns of residents - and the problem of access to wastewater infrastructure and sanitation - take a back seat, while engineering works as markers of development are at the centre of attention. At best, slums are described as entitled to a list of infrastructural equipment. The provision of toilets, as well as internal drainage of slums, for example, is addressed by the Slum and JJ Department of the MCD. ${ }^{3}$ Yet, attention remains to be on asset creation, rather than on specific environmental or social outcomes.

Those who advocate for the urban poor's entitlement to services and their human rights to water and sanitation insist, in contrast, that better living conditions have to be achieved (Batra 2005; Ali 2006). Dysfunctional or dirty public toilets and blocked drains or sewers cannot be accepted as 'service provision' in the eyes of activists and NGOs. Picking up on the issue of blocked drains, government actors such as the Department of Environment Management Services of the MCD hold that these problems are caused by residents' faulty solid waste disposal practices. Questions of health prevention (including waterborne diseases such as malaria and dengue), again, are the responsibility of the Health Department of MCD, which treats problems resulting from stagnant water through extensive fogging of insecticides and check-up drives in households.

\section{Problem framing: wastewater and the role of experts}

Having considered some of the policies and interventions to address wastewater, it is important to go a step behind these and question the very production of knowledge on wastewater management, which is at their base. A recurring theme, yet often taken for granted by the research community, is the primacy granted to technical considerations in the course of proposing appropriate interventions. River pollution, an important dimension of the wastewater crisis, is one area that has largely followed a technocratic trajectory, focusing mainly on the implementation of 'hardware' solutions. However, interviews with scientists suggest that technical trajectories should not be regarded as isolated entities. On the contrary, these are reproduced by communities of expertise, and institutionalised through various practices (Jasanoff 1990).

A useful entry point for exploring how these considerations play out in Delhi is the Central Pollution Control Board's (in short, the Board) rationale for planning water quality restoration programmes. A powerful conceptual tool which has emerged from the Board for planning water quality restoration is the Designated Best Use (DBU) framework. According to the DBU, water quality restoration is organised on the basis of achieving a range of desired human uses. Given the very large number of water bodies in India, using this concept was envisaged as a tool to help prioritise pollution control activities; it is supposed to be cost-effective and provide more concrete guidelines for regulators and policymakers. A direct outcome of this process has been a nationwide water quality monitoring network for classifying water bodies according to their designated best uses. The information is regularly collected, analysed and published in official reports that inform interventions. River action plans (e.g. the Ganga Action Plan) are partly designed on the basis of this approach.

Despite the DBU's purpose to simplify the work of decision-makers, it has several implications for how wastewater is routinely interpreted and acted upon by expert-led institutions. One important implication is deciding what are to be regarded as 'credible' sources of information for assessing wastewater. The prominence ascribed to physico-chemical criteria such as 'biological oxygen demand' and 'dissolved oxygen' has been influential in characterising wastewater solely through technical knowledge. In this context, the prestige Board scientists associate with handling numerical information is prominent. A senior scientist leading the Board's monitoring programmes said, 'Our power is that we have the 
data, people come to us for information'. This statement, while separating the authority of the Board as providers of credible knowledge and putting emphasis on technical interpretations of wastewater, illustrates how difficult it is to accommodate alternative assessments emerging from non-technical stakeholders and diverse interest groups into this evaluative framework. It also explains why, for instance, it is often considered difficult by Board members to trust civil society and NGOs to conduct assessments that are relevant to decision-makers. As explained by a junior engineer: 'The Board cannot rely on NGOs for water quality testing; their role is much more about creating awareness'.

The perceptions of civil society and environmental groups suggest an increasingly more cynical and distant view towards the Board's claim to expertise. This is partly because of the way the Board allocates specific roles and responsibilities to civil society groups and environmental organisations. According to the director of a small NGO operating in Delhi, the Board's approach to addressing worsening levels of water quality operates within a narrow framework of science: 'The bandwidth within which the technical solutions to water quality are being created by the Board is extremely narrow'. This in turn, is frequently perceived as weakening significantly, civil society's willingness to work with the Board members. As it is described in interviews, in most cases civil society representatives routinely struggle to have their own research and findings recognised by regulators.

Another less understood dimension of the functioning of the Board is that, although during interviews scientists claim to base their decisions on 'technical' considerations alone, in practice, decisions around the type of water quality problems that should be prioritised in formal policy and planning are also strongly influenced by 'economic', 'religious' and 'political' factors. For example, the Board scientists tend to agree among themselves that the Ganges figures much more prominently in the assessment of water quality, partly due to its 'religious' significance, but also because of the central role of 'river basins' as natural reservoirs for supplying drinking water to expanding cities and small towns. In Delhi, the strong convergence of urban middle-class environmentalism with concerns around the Yamuna water quality, particularly the more polluted Delhi stretch, has given rise to a series of judicial interventions from the Supreme Court, to raise the quality of the river to bathing status (Gatade 2000; Dutta and Peace Institute Charitable Trust 2009). This in turn has meant that the Board has turned much of its own resources and efforts towards monitoring the pollution of the Yamuna. The 'river basin' indirectly places significant influence on the ambit of the Board's monitoring strategies and the process of prioritising information for wider dissemination in the public domain. Curiously, however, the fact that 'some' rivers have gained more prominence among experts because of a host of political, religious and economic influences, as opposed to 'technical' aspects alone, rarely figures in the Board scientists' discourse.

What are the shortcomings of the current expert paradigm for addressing contemporary wastewater problems? A particularly serious omission is that it fails to adequately capture that different types of exposure are presented to different social groups residing in different parts of the city. Sampling stations to monitor untreated wastewater are designed to capture larger water quality trends at the level of the 'river basin', and within that, at the level of 'the state', or 'the union territory', but not those places where people are in direct contact with the wastewater. The same field of visibility can also be traced in the Board members' discourse. For example, the view that 'our role is to monitor rivers, and slums are not our responsibility' held by the Board's water quality monitoring programme leader, is widely shared among many Board scientists. A powerful assumption which flows from this approach is to regard people's exposure to be a concern addressed by other departments or policy areas of the executive. A Board scientist of the pollution monitoring division anticipating our queries about the human dimension of wastewater once said, 'We don't really do health [epidemiological] studies this is the responsibility of the Health Department'. Because of this fragmentation of roles, there is very little flexibility both in the choice of areas for monitoring untreated wastewater and in the way scientific information is typically used by policymakers to make decisions for its management at the city level. 


\section{Wastewater in residential colonies: the practical, health and social dimensions}

The distance created between expert-led science and citizen 'lay' knowledge becomes more evident when we shift our analysis away from the Board to the level of the residential area, or the 'colony'. For residents exposed to wastewater in their living environments, and this concerns particularly poorer urban residents, wastewater is part of a different discourse firmly embedded in the everyday life experience. In our view, it becomes a problem when these experiences are not recognised as legitimate sources of information by local state representatives, let alone forwarded to arenas of policymaking. As citizens try to put across their views on the causes of the problems and subsequently about the share of responsibilities between the state and the public, and the type of interventions needed, local struggles to formulate a political agenda take place.

The everyday dimension of wastewater exposure is apparent in data from an approximately 30-year-old unauthorised colony in East Delhi inhabited mainly by working-class Muslims, which has a highly uneven state of infrastructure development. Wastewater-related problems in this context refer most importantly to practical concerns around wastewater stagnation and overflow of drains into the street and houses.

Where the streets are not concreted, they are muddy and uneven, and wastewater partly flows in the middle of the street, or stagnates in pools. The dirt from wastewater stagnation is regularly described as so prevalent that even in the dry season, people cannot go outside barefoot. Water pools in the street make walking difficult, and several respondents had fallen in slippery streets before. This is especially the case for children passing open ground in which wastewater accumulates on their way to school. Spoiling school uniforms on the way was a repeated complaint of mothers. Where streets are concreted and raised, many houses have become buried below street level. Inhabitants therefore feel that upgrading is 'good for the road, but bad for the house', so that they are 'happy and sad, both'. Problems have also shifted with time: while overflow in the streets now only happens in the rainy season, and is not as prominent, overflow in low-lying houses has increased considerably. A respondent reported how her family was obliged to live on the first floor in the Monsoon months, 'But to get out of the house we have to go down and get wet'. Also, where septic tanks are below street level, latrines are not used and/or inhabitants have to empty the septic tanks by hand or by motor pump. If the difference in level is small, latrines are disused in times of heavy rain, as water then starts flowing into the septic tanks.

Moreover, people complain about health problems related to an overall lack of cleanliness, and especially the dirtiness of the open space.

Stagnating wastewater, too, residents explained, is a severe health risk, as it allows mosquitoes to breed. Water taps that are susceptible to flooding by wastewater can lead to contamination of the drinking water source. Water quality in this context is judged more frequently on the basis of the poorer citizens' own criteria, such as aesthetic considerations, colour and appearance; ${ }^{4}$ and far less on the basis of formally prescribed physicochemical parameters.

The daily struggle to cope with wastewater becomes inseparable from a discourse that emphasises the loss of dignity and status in the society. Residents complain that the street is not looking good, and frequently complain about the bad smells emanating from the drains. People feel disgust: 'I can clean as much as I want inside; as soon as I go outside I feel dirty', a resident said. They complain that 'Our colony is no longer clean; we are bound to live in filth and bad odour'. Moreover, inhabitants feel embarrassed in front of guests: 'Outsiders from approved colonies say, 'it stinks so much, how can you live like this?', (interviewee). The dirtiness exposes them to ridicule: 'When our relatives come from UP [Uttar Pradesh] they are mocking us because it's so dirty', a woman recounts.

In the view of some residents, the problems posed by untreated wastewater are not entirely because of a failure of the state to provide sanitation services to the poorer colonies. Problems are also linked to daily conflicts between neighbours. For example, certain households do not want to contribute to unblocking the drains - reasons being named as their 'mentality', but also because certain houses are built very high and do not face indoor overflow.

On closer inspection, problems are strongly linked to how urban citizens perceive their social position 
in the larger city. Those with exposure to other parts of the city or with vivid memories from their home village or town compare their colony as a whole extensively with other areas, negotiating their space in the social web: first of all, they compare with Hindu areas; second, they compare with nearby authorised colonies, and the residence of their Member of Legislative Assembly (MLA); third, they compare smaller towns or villages in Uttar Pradesh. In contrast with all these areas, inhabitants see their colony as dirty:

This is a third class area, I would prefer to call it fourth class (...) [the neighbouring authorised colony] is second class. In first class areas even the cars are not covered, you can't find any dust on them and the trees look like [they have been] washed, but here even inside the house there is so much dust.

The cleanliness of authorised colonies is thus the goal and the bar against which inhabitants measure their colony's status.

Exposure to wastewater is also used to negotiate the relationship with the state. Especially in unconcreted streets, inhabitants relate the wastewater situation to their poverty: 'In the whole C-Block this is the dirtiest street', an inhabitant judges. As they have accepted that 'nobody listens' to the poor, poverty is equated with powerlessness, which excludes residents from state interventions. As a result, they are obliged to live in a dirty space. Far from recognising this as a serious consequence of wastewater-related problems for urban cohesion and social justice, local state representatives do not seem to reflect on these inequalities. Inhabitants report that politicians and the administration 'think those people [in unauthorised colonies] are not even aware', an attitude that justifies the neglect by the state representatives.

The various ways in which wastewater becomes intertwined with poorer urban citizens' living surroundings raises a range of concerns that tend to be downplayed by experts, but also by local state representatives. Neither practical problems of transportation, nor damages to houses or health concerns are addressed seriously at the local level. Rather, local politicians and the administration focus on 'dirtiness' in their descriptions of the problems the colony faces. But the complaints about dirtiness that residents voice and that put emphasis on the individual inability to solve the problem is turned on its head outright by the majority of local state representatives. For them, the environment of the colony is dirty because of its residents' moral and educational shortcomings: inhabitants are dismissed as 'not aware', backward, and following illegal practices such as unlicensed slaughtering and buffalo rearing, thus creating the wastewater problems themselves. Regarding conflicts, too, local politicians and bureaucrats argue that these are not due to wastewater; rather, residents are described as quarrelsome and uncooperative in general.

Residents resist these ascriptions of lack of awareness as a reason for the problems they face, and put the ball back into the realm of the state. They identify themselves as a large vote bank, and report that 'In Delhi, 85 per cent of the colonies are illegal'. Living in an unauthorised colony is therefore nothing to feel bad about. Rather, as citizens, and moreover part of the majority, they feel entitled to certain services. This reflects research by Chandhoke (2005) and Harriss (2005) that showed that the responsibility for public services such as wastewater drainage is located in the government by the urban poor especially. Yet, local state representatives tie residents' entitlements to the performance of certain duties, which are advocated under the label of 'cooperation' with the state. Responsibilities to the poor and the involvement of the state are thus kept limited.

\section{Conclusion: introducing citizens' experiences into wastewater debates}

The article has explored different framings of wastewater ranging from those discussed at city level, to the often taken-for-granted expertdriven framings, to those of citizens regularly exposed to wastewater. We have argued that the gap between 'expert' and 'lay' perspectives on wastewater is a potential arena of struggle and intense politics - and yet, the power divide is such that these politics are hardly ever played out between residents and experts directly. Contestations take place between professionalised civil society actors - new experts in their own right - and technical experts; they are also found between residents and local bureaucrats as well as politicians, themselves more often dismissed as uneducated by higher levels of governance. The gaps in perceptions, 
but also the gaps of communication pose a serious challenge for policymaking that seeks to address citizens' concerns. They strengthen the call in the New Delhi Statement 'to ensure that national plans and programmes are responsive to community needs and desires' through community management (Principle 3), as well as the Dublin Principle No 2 that requests 'that decisions are taken at the lowest appropriate level, with full public consultation and involvement of users in the planning and implementation of water projects' (United Nations 1990). The described gaps, moreover, raise strong questions about the legitimacy of different kinds of knowledge. While expert knowledge is powerful, and frequently finds its way into policy documents (subsequently directing massive flows of public expenditure to address at least 'in theory' the problem of river pollution), citizens' knowledge is rarely gauged by governments, and even less used to formulate interventions. The case study on the unauthorised colony has shown how the discursive environment broadly delegitimises people's perception and knowledge about the nexus between infrastructure, practices, solid waste, wastewater and local needs. Effectively putting wastewater on the political agenda in such a context thus becomes near to impossible.

Significant opportunities exist therefore for strengthening interaction and exchange between actors that influence policy outcomes or experience their consequences in different ways. The environmental regulatory authority's emphasis on river pollution often means that problems of untreated wastewater inside the poorer colonies do not feed into national level policy processes as easily as river basin concerns. This tendency could be reversed by allowing for greater flexibility in the approaches used to monitor water pollution, as well as creating a

\section{Notes}

1 We borrow the use of the terms 'expert' and 'lay' from Wynne (1996).

2 Direct quotations cited in this article are drawn from interviews conducted with scientists and engineers working for the Central Pollution Control Board (CPCB), as well as diverse residents, including those from an unauthorised colony in East Delhi and an urbanised village in the Eastern periphery of Delhi; politicians; local more meaningful dialogue with civil society in the appraisal of different policy options. More important still, citizens' knowledge needs to be fully integrated into decision-making. Citizens' accounts not only address the politics of wastewater in an elaborate way, they also direct attention to complex social and environmental impacts of untreated wastewater at the local level. But, the fact that local state representatives do not recognise citizen accounts on wastewater as a legitimate source of knowledge poses a significant barrier for the integration of expert and lay perspectives to become realised.

Finally, this article raises some interesting implications for the way the problem of untreated wastewater is positioned in wider policy debates. At the international level, managing untreated wastewater often lacks its own policy space and instead becomes situated at the intersection of several, and sometimes competing sector-driven mandates, including water and sanitation, water resource management and public health. The Delhi experience shows that even though wastewater is captured under several headlines, as it turns out, it is a complex problem with political implications that often elude the imagination of urban planners, scientists and policymakers. Therefore the question that needs to be asked is: Should 'wastewater' have its own policy space in international debates? Alternatively, how can greater policy involvement with the problems discussed in this article be achieved through existing institutional and sector driven channels? At the moment, each sector is driven by its own mandate and policy targets, critically undermining the central role of managing untreated wastewater, and the relevance of this for achieving important development targets (be it in the realm of water, sanitation or health).

administrative staff and higher ranking officers. For reasons of confidentiality the names of those interviewed as well as specific sites of the study remain anonymous.

3 Since 2010, this department has been superseded by the Delhi Urban Shelter Improvement Board under the State Government.

4 A fact highlighted in interviews in the urbanised village. 


\section{References}

Ali, S. (2006) 'Managing Slums in Delhi', in S. Ali (ed.), Managing Urban Poverty, New Delhi: Uppal Publishing House: 432-53

Banerjee, S. (2001) 'Urban Governance and WSS Service Delivery Issues', presentations at the International Conference on New Perspectives on Water for Urban and Rural India, New Delhi

Batra, B. (2005) Entitlement to Services and Amenities in JJ Clusters, JJ Relocation Colonies and Other Non-planned Settlements in Delhi: An Overview, www.isst-india.org/PDF/Entitlement \%20to\%20Services.pdf (accessed 25 July 2010)

Baud, I. (2011) Spatialising Knowledge in Urban Governance, CSH-CPR Urban Workshop Series, New Delhi

Black, M. and Fawcett, B. (2008) The Last Taboo: Opening the Door on the Global Sanitation Crisis, London: Earthscan

Chandhoke, N. (2005) "“Seeing” the State in India', Economic and Political Weekly 40.11: 1033-9

Chandra, R. and Aneja, R. (eds) (2004) Water Environment and Sanitation Assessment, New Delhi: Isha Books

Chaplin, S. (2011) 'Indian Cities, Sanitation and the State: The Politics of the Failure to Provide', Environment and Urbanization 23.1: $57-70$

CPCB (2004) 'Status of Sewerage and Sewage Treatment Plants in Delhi', Control of Urban Pollution Series: CUPS 2003-2004, New Delhi: Central Pollution Control Board

CSE (2009) Review of the Interceptor Plan for the Yamuna, Centre for Science and Environment, www.cseindia.org/userfiles/CSE_interceptor _analysis.pdf (accessed 13 July 2011)

CSE (2007) Sewage Canal. How to Clean the Yamuna, New Delhi: Centre for Science and Environment

Deb, K. (2004) Reforms in Drinking Water and Sanitation, New Delhi: TERI Press

Dutta, R. and Peace Institute Charitable Trust (2009) Unquiet River. An Overview of Select Decisions of the Courts on the River Yamuna, New Delhi: Peace Institute Charitable Trust, www.peaceinst.org/publication/book-let/The \%20Unquiet $\% 20$ River\%20An\%20Overview\%20 of $\% 20$ Select $\% 20$ Decisions $\% 20$ of $\% 20$ the $\% 20$ Courts\%20on\%20the\%20River\%20Yamuna.pdf (accessed 10 January 2010)

Engineers India Ltd and CH2M Hill (India) Pvt Ltd (2008) Laying of Interceptor Sewer along Najafgarh, Supplementary and Shahdara Drain for
Abatement of Pollution in River Yamuna, Detailed Project Report, www.indiaenvironmentportal. org.in/files/DPR_MAIN\%20VOLUME.pdf (accessed 26 November 2011)

Gatade, S. (2000) 'And Quiet Flows the Yamuna: A Court Order and its Aftermath', Mainstream, 9 December: 6-11

Harriss, J. (2005) 'Political Participation, Representation and the Urban Poor', Economic and Political Weekly 40.11: 1041-54

Jasanoff, S. (1990) The Fifth Branch: Science Advisers as Policy Makers, Cambridge MA: Harvard University Press

Keeley, J. and Scoones, I. (1999) Understanding Environmental Policy Processes, Brighton: IDS

Mavalankar, D. and Shankar, M. (2004) 'Sanitation and Panchayats in Infrastructure', India Infrastructure Report 2004. Ensuring Value for Money, 3-i network, New Delhi: Oxford University Press: 314-24, http://3inetwork.org/ reports/reports 1.shtml (accessed 13 January 2012)

McGranahan, G.; Jacobi, P.; Songsore, J.; Surjadi, C. and Kjellén, M. (2001) The Citizens at Risk: From Urban Sanitation to Sustainable Cities, London: Earthscan

Movik, S. and Mehta, L. (2009) Going with the Flow? Directions of Innovation in the Water and Sanitation Domain, STEPS Working Paper 29, Brighton: STEPS Centre

NSSO (2003) Condition of Urban Slums 2002: Salient Features, NSS 58th Round (July 2002-December 2002), New Delhi: GoI Ministry of Statistics and Programme Implementation and National Sample Survey Organisation, www.domainb.com/economy/general/2005/pdf/Urban Slums.pdf (accessed 1 December 2011)

Prakash, G. (1999) Another Reason: Science and the Imagination of Modern India, Oxford: Oxford University Press

Prasad, V.B.R. (2002) 'Municipal Wastewater Management - Indian Scenario', International Conference on Water Quality Management: South Asian Perspective, Jaipur: International Life Science Institute: 263-72

Sakdapolrak, P. (2010) Orte und Räume der Health Vulnerability. Bourdieus Theorie der Praxis für die Analyse von Krankheit und Gesundheit in megaurbanen Slums von Chennai, Südindien, Saarbrücken: Verlag für Entwicklungspolitik

Singh, R. (2009) 'Wastewater Problems and Social Vulnerability in Megacity Delhi/India', PhD thesis, Department of Geography, Cologne: University of Cologne 
United Nations (1990) New Delhi Statement, Global Consultation on Safe Water and Sanitation, 1990, www.ielrc.org/content/e9005.pdf (accessed 1 December 2011)

Wynne, B. (1996) 'May the Sheep Graze Safely? A Reflexive view of the Expert-Lay Knowledge Divide', in S. Lash, B. Szerszynski and B. Wynne (eds), Risk, Environment and
Modernity: Towards a New Ecology, London: Sage Publications

Zimmer, A. (forthcoming) 'Everyday Governance of the Waste Waterscapes: A Foucauldian Analysis in Delhi's Informal Settlements', $\mathrm{PhD}$ thesis, Department of Geography, University of Bonn, Bonn 